\title{
The American City
}

\author{
MICHAEL STANTON \\ Tulane University \\ USA
}

A city divides into forms and attitudes, into significances, in the most political of senses, into episodic impressions, grand narratives and great collective generalizations. Cities are the vehicles for vivid nostalgia and are often the victims of banal cliché, both in the making of their form and in the way they are perceived. They are collaborative works, and, like works of art, they are conceived passionately, formed imperfectly, understood and misread by a continually transforming and distracted collective. Cities embody myth and fact, blurring the border between the two. All this applies especially to the fraught history and troubled body of the American city.

The fields of the Midwest, the grid laid over city and country, the infinite variation of urban and agricultural expedience within the square miles and their subdivisions - from the air like Mondrian or Klee - to the city block and the individual lot - the physical fact of North America - this rural-urban landscape is the largest conceptual design project ever effected.

A group of American philosophes made the United States. It was the homunculus of Thomas Jefferson, Benjamin Franklin et. al. - the experimental laboratory for this patrimony.' No matter that it was already occupied by both natives and Europeans and their slaves, America seemed to provide an untouched and fertile field for all the passions that drove the troubled 18 th-century consciousness. It was vessel, virgin territory, and the national myth of fecundity and virtue remains potent.

In our day everything is pregnant with its contrary...Even the pure light of science seems unable to shine but on the dark background of ignorance. All our invention and progress seem to result in endowing material forces with intellectual life, and stultifying human life into material force.

\section{- Karl Marx ${ }^{2}$}

The American city embodies extreme paradox, primarily in the strident contradiction, endemic to the totality of American culture and politics, between utopian-idealistic and pragmatic-social Darwinist impulses. America thrives on such oppositions - between isolation and empire, puritan and libertine, bellicosity and pacifism, secular and ecclesiastical, agrarian and industrial, individual and society, to name a few. Maybe the most extreme contradiction is between aspiration and fact in the Americas, between a show of fanatical idealism and the plain and often sordid actualities of a tough frontier. This chasm between rhetoric and fact has widened at times so as to verge on national psychosis. Paradox resonates in our cultural production and has produced the anxious dichotomies that characterize our notions of ourselves, and by extension, of the modern age, of which the United States remains the exhausted torch-bearer.

Despite the agrarian-utopian vision of some of the founders of the United States, it was in the New World city that much

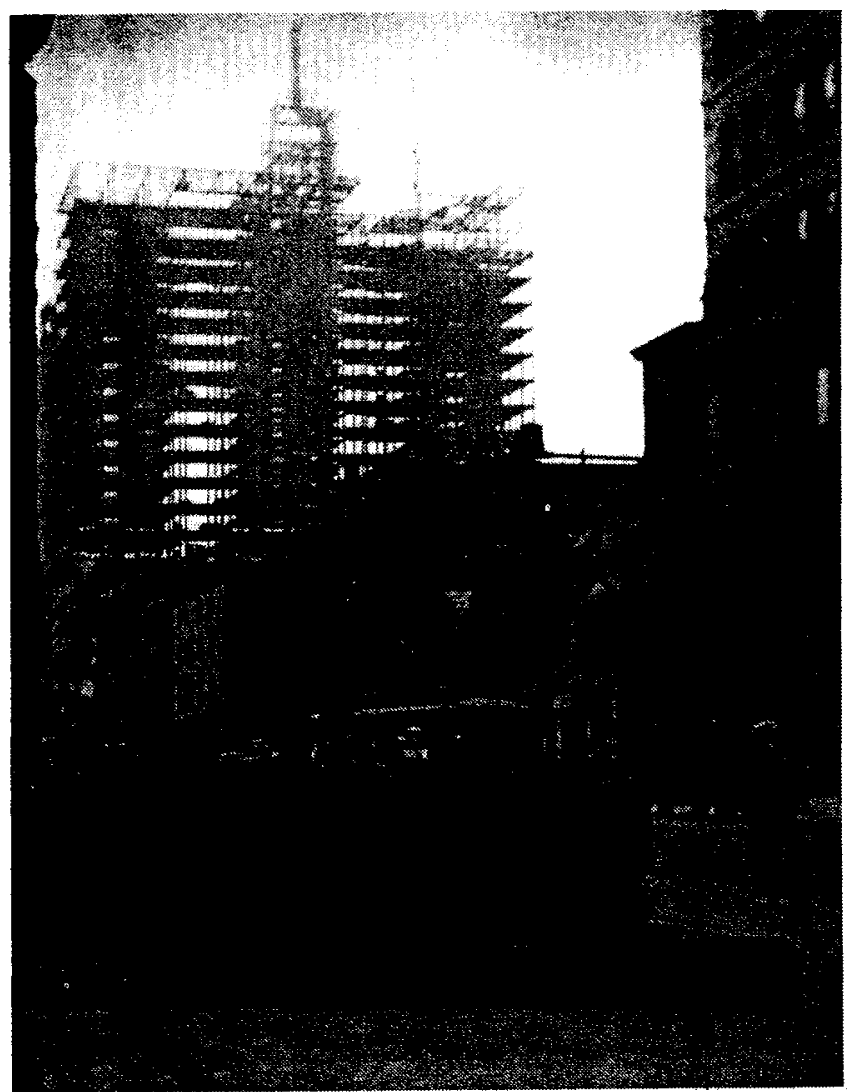


of the most strident desire of 18 th-century social philosophy was able to take hold, for cities are the traditional crucible of change, and it was there also that the severe facts of the Industrial Revolution, the practical sibling of the Enlightenment, were realized. The American city was, and remains, the city of theory and the city of fact, the two obscuring each other.

'Is New York such a labyrinth? I thought it so straight up and down - like Fifth Avenue. And with all the cross streets numbered!...If you knew how I like it for just that - the straight-up-and-downness, and the big honest labels on everything!'

He saw his chance. 'Everything may be labeled - but everybody is not.

\section{- Edith Wharton ${ }^{3}$}

The utopia of commerce was realized in the American city, the crowded boulevards teeming with vehicles, compressed and filled even more by the vertically extruding gridiron, dominated by cathedrals of transport and transaction, capital of capital, citadel of speed, efficiency and a clean slate. Hugh Ferriss' renderings convey the fraught romance, within the three-dimensional orthogonal matrix, of the most idealistic and the most crass and real forces of economy and progress. These oppositions produce impossible conjunctions of hope and greed, succor and exploitation, the imaginary and the rudely real.

The grid itself, that inevitable mark on the American landscape, rural and urban, with all its Cartesian associations, is an ideological form arguing at the same time for equity and authority. This mark extends to the three-dimensional frame of the American building. Chicago is the great city of the extruded grid, expanding in the $Z$ dimension almost infinitely, expressed as the body and the decoration of buildings each of which reiterates the totality of the city.

The appeal and the inspiration lie of course, in the element of loftiness, in the suggestion of slenderness and aspiration, the soaring quality of a thing rising from the earth as a unitary utterance, Dionysian in beauty... In Chicago the tall office building would seen to have arisen spontaneously, in response to favoring physical conditions, and the economic pressure as then sanctified, combined with the daring of promoters... The future looked bright. The flag was in the breeze.

- Louis Sullivan ${ }^{4}$

Following the Greeks, the Romans gridded their vast Empire, attempting to arrange its incomprehensible magnitude, stretching from Persia to England to Morocco. Likewise, and with equal presumption and anxiety, the philosophefounders imposed the universal datum across the new and uncharted land.

The grid, in the uniform and comprehensible disposition of its equal warp and weft, is arbitrary and symbolic. Its logic derives from convention, not from any a priori inevitability and certainly not from pure convenience. In fact, it is not the most efficient of plans for cities, as is make clear by the way they develop when undesigned. The grid does suit the needs of development, however. It represents a pervasive belief in limitless opportunity and essential expansion, inevitable in the prescriptions of frontier and capital. What is perfect about the grid, as it was for the decimal hierarchies of the Romans, is its absolute sameness, implying conformity and possibility. Jefferson envisioned an infinite tapestry of available agricultural parcels, of perfect physical equality for each citizen, a tapestry of potential, ambition and fortitude - noble savages, each developing their identical piece of the endless and non-urban landscape, bound together by shared values and dreams, structuring a new nation.

The oxymoronic construct of autonomous citizens, of rugged individualists who are good civil creatures, who are personally free within a taut societal frame, is another of the paradoxes which frame city and nation. An absolute and rigid structure containing infinite difference and elaboration does seem basic to America's self-image. Jefferson's Academical dream may have found its lowest common denominator as the American suburb. Certainly many of the same desires resonate almost inaudibly there. It is ironic that at the center of many American cities the Jeffersonian vision is being realized. In St. Louis the streets lie across an empty landscape returning to nature, sometimes cultivated by urban gardeners.

In the grid of city and country, then, there existed an armature that could hold both the most idealistic and pragmatic of impulses, and there what Leo Marx calls "the contradiction between rural myth and technological fact" could be accommodated, even organized. This then makes the difficult ideological entity that is the United States quite possible and practical in fact, and it makes the American city an affirmation of the generative power of contradiction. For while hallucinatory in its image of itself, this has been a nation run by, and for the benefit of, tough progressives and capitalist realists. It is extremely practical and often quite plain, static and urban. There never were many cowboys, and there have always been a lot of clerks.

"The sublime (in America) comes from the fact that anything can happen." All material fantasies, all extravagances, come into existence and as quickly disappear. Within the grid, and because of its very anonymity, the industrial city engaged in an orgy of heightened symbology. Unprecedented verticality and density accompanied a riot of pseudomonumentalism. In America and in 19th-century Europe to a lesser extent, with their new and diverse centers of power, and in the imposing impartiality of their plans, the monumental proliferated and distorted. Expressive hierarchies became anxiously overblown, consuming the metropolis in a riot of surplus architectural signification that is most extremely reified as Manhattan. The grid, by nature, pushes all monuments to the side. They must fend for themselves becoming one of what Tafuri calls the "...exceptional events which enclose the paradox of the metropolis within themselves."

In such a non hierarchical field the clamor becomes 
increasingly shrill. Along lower Broadway between Union Square and downtown Manhattan, the buildings elbow and jostle each other, each arguing the near-ecclesiastical monumentality of its particular mercantile institution, each finally subsumed in the block and its regulator, the grid. The semantic pressure is intense.

In New York, it took John D. Rockefeller Jr. and the RCA complex to overcome the omnipresent gridiron, and then only by making a mid-block street. The Housing Authority did what even the Rockefellers couldn't and closed the streets to create mega-block projects, to finally break the absolute hegemony of the orthogonal, which was only violated historically by the prime icons of the industrial age, Grand Central Station, the Public Library and Central Park - monuments to transport, knowledge and the pastoral.

The creation of mega-blocks, whether for housing or other forms of development, corresponds directly to the centralization of urban capital in the hands of either entrepreneurs or public authorities. As the pressure mounts, the figure fuses. Monopoly, be it private or state controlled, does away with the intractable illusion of equality while simultaneously claiming to ratify it.

Meanwhile the city develops the downtown block as a "compound", an armed enclave. The atrium building with its interior "public space" controlled by guards, seems ultimately cynical as a gesture toward both the vitalization and the problems of the urban fabric. Washington, the Capital besieged by its own castoffs and underclass in the Reagan years, resorted to a systematic enclosure and fortification of the block in dozens of new office buildings., using "contextualism" as an excuse. Isolation from inherent societal ills thus finds form in the current redevelopment of downtowns, with their controlled safe pedestrian tubes above the dangerous streets, or tunnels below, stratifying the class designations that shape the city. Two tiered circulation ends the heterogeneous life of the boulevard. The flâneur is disengaged. In New Orleans quaint and proliferating street car lines serve tourists and the middle-class lunch crowd while grim buses move the underclass, routes separate.

In the American city the street itself is civic space and that cardinal of American qualities, movement, is therefor the point. Americans do not generally linger in public space, at least they did not before the shopping malls began to approximate the life of galleria or market square as the nation belatedly discovered leisure. But in America, the public replaces the civic. Codified with the first words of the Declaration of Independence and stemming directly from The Social Contract, the concept of the public sits with the pastoral at the ideological center of the nation's sense of itself as a consensual entity. Frances Perkins said of Robert Moses "He loves the public, but not as people." American cities institutionalize the national ethos in many vast, and untended, parks and recreational spaces. These feral simulations return that refined commodity so precious to the Enlightenment to the savage practicality of the industrial city.
America has remained hostile to the city as a concept, seeing it a pragmatically necessary evil, inheriting this prejudice from Jefferson and the pastoral. American's tend to think of themselves as non-urban. The city, and its arbitrarily designated, and artificial, foil nature, are both objects of extreme awe and apprehension. In the ultimate confusion of the present day, the city is a "jungle" prowled by predators.

Americans share an antipathy to the urban inherited from their ancestors in flight from whatever culture they left, be it one that persecuted them or impoverished them, or both culture identified by the image of the city that has always been its primary metonym. The citizen is likely to distance him or herself, to see the city as the place of a virulent form of corruption, anti-puritan by nature, blurred and complex in form. Of course, this hostility has direct political-economic ramifications. The city becomes like the bad dog chained in the backyard of culture, deprived of tax-revenue sustenance, becoming daily meaner and more dangerous, kept barely alive, a necessary evil, a foil and pharmakon - like the underclass it has come to represent. The suburb or the neighborhood are felt to be other than the very city they compose.

On the other hand America engages in an ongoing romance with the machine, the icon of progress and redemption. Perhaps it was the emphasis on movement, coupled with the love of the machine and the powerful force of the capital that machines accumulate around themselves, that joined the innate hostility to the city inherent in Jefferson's sentiments to produce the post-industrial city, the sprawling megalopolis that encircles and drains industrial American cities and sometimes seems to function without a core or to be in the process of retroactively inventing a core to justify the vast plain of suburbanism that already exists. The very alienation that sits at the core of the modern and that clearly forms the strengths and weakness of American culture, an alienation that is both productive and anxious, also makes a city of the periphery, a city where all urbanism is outside, identified by absence.

Los Angeles, Houston, Atlanta, but also and very significantly, Mexico City - the world largest - Sao Paolo, Toronto, these other American sprawls are included in this urban type and argue for its hemispheric origins and universality. It seems chaotic and raw. In fact, it is extremely organized and numbingly repetitive. It is only marginally specific or regional tending toward a universality which is reflected in the diminishing accents of its residents.

The post-industrial city is almost without hierarchy or monumentality, conditions emblematic of the bombastic industrial city. Cities have always reflected, in their physical form, the instruments, both political and actual, of their production. New York is the machine of the 19th century: loud, thrusting, insolent, sleek, big. From the air, the spine of the island is body of vastly complex engine, prickly with mechanism. LA is like another machine: silent, electrical, networking and synaptic, universal thus anonymous. Seen 
from hills, it stretches like an endless circuit board. Paul Virilio writes "Behind the electric megalopolis the city knows no rest." "8

This then is the city of the Second Machine Age, as clearly as the industrial city was made by and represented the first machine. The gigantic turbine, the smelting vessel, the lathe, the engines took their places as objects of wonder beside the greatest artistic and decorative products of culture at the grand expositions of the 19 th century. The new machines are different. First of all they are made, in bulk, by other machines. They are not so magnificent, like photographs next to paintings. The second machine is often electronic, without the pumping pistons, the exposed and beautiful mechanism, the shafts and tendons of the first machine. The second machine serves, producing comfort, pleasure, distraction, convenience, mobility. It is personal and expendable. An exquisite formula of puritan consumption is its point. It is the next frontier and it is this machine - the automobile, the television, the air-conditioner and now the computer - that shapes our new urbanism. Decorated, polished, souped-up, chopped and channeled, the car promises a universal mobility and becomes the principle personal signifier of the 20th century, replacing in importance the dwelling itself. The V8 convertible out on the highway - here the lost frontier still could be approached for a fleeting energy-drunk moment. The illusion of mobility, pivotal to the dream of the immigrant and to the myth of the nation, was available and hysterically exaggerated as its actuality faded.

While the private automobile clearly allows for an exponential expansion and distention of the fabric of the city, perhaps too much has been made of the difference between the city and suburb, between industrial and post-industrial urbanism. The fabric of the post-industrial city is really a transformation of the industrial city, a flattening and widening, to the coefficient of the vehicle. It represents a change of measure and sentiment, not a complete reversal. It is the scale that has changed. The flaneur of the 19th century wandered the boulevards in fleeting contact with the teeming denizens of the new metropolis. The 20th-century flaneur cruises the boulevards in low-rider or jeep, in an even more removed and accelerated promiscuity of contacts, but this time the contacts are not with the shadows behind tinted windshield and sunglasses, but with the mobile shell that theses fragile figures have pulled around themselves.

A characteristic of the modern city is the sameness of the private environments of work, home and travel between the two. The repeated format of screen with controls below, breaks down the experiential difference between television, computer and automobile. It also brings into question the discriminatory powers of those caught in the cycle of their use. The portable channel and VCR controls, the computer keyboard, and the buttons and dials of the car with the replication of the apparatus of work and home completed by the car-phone, all control very different blocks of information and demand different levels of response and attention, but the uniformity of the environment seems to

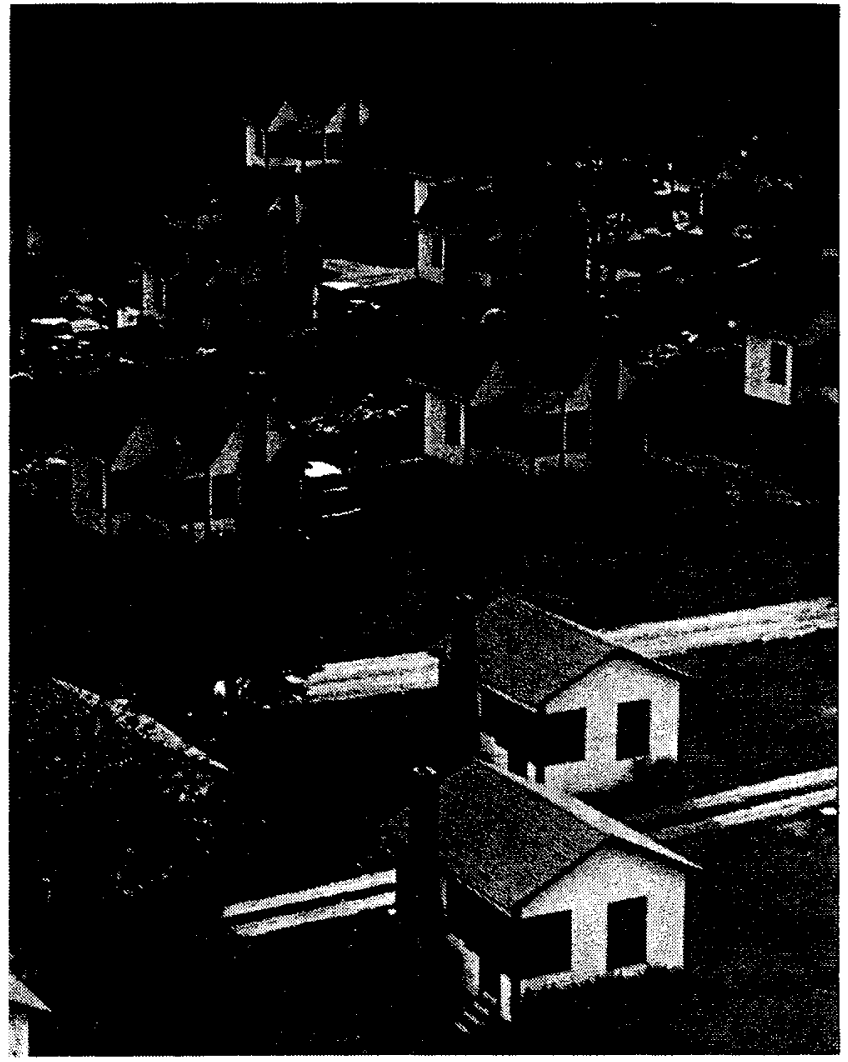

downplay that difference, lulling and deeply disengaging an uncritical consumer public.

Postindustrial urbanism is pervasive and vast, consuming enormous tracts of land at the periphery of all old cities and defining the totality of new cities like Miami, born in this century. In between the commercial strips that often correspond to the original mile grid of the agricultural-utopian fabric, are the residential subdivisions, composed of singlefamily homes isolated on their lots, pseudo farms, or in pseudo villages of town-house communities, each attached building arguing its isolation by bumping in and out a few feet. Parking lots and subdivisions repeat the typology of boxes in lines, brutally uniform within the look of individuality. The energy of the vertical extrusion of the block that characterized the industrial city here goes horizontal with equal vehemence. The Chrysler Building, with its fins and steel ornament, becomes, in the '50s, the Chrysler itself, a land rocket. Monuments scatter through this diverse tapestry at a scale that subsumes them within the existing typologies. Objects supersede ensembles. Almost every building, from shopping mall, to church, to office block, to gas-station, to private home, conforms to the basic morphology of object on lot, iconic thing at the center of field.

All is simultaneously undefined and precise: undefined in its entropic extension and precise in the immediacy of forms. Space is simultaneously omnipresent and trivial. The rhetoric of the suburb argues that the best of garden and city join there. In this case, city and garden are both idealizations. As 
an expression of a debased ideal crossed with the tough pragmatics of the frontier and of the realities of speculation and development, the modern pastoral finds form in the tranquil simulacra of Whispering Pines or Brookhaven Estates. Three types of lines determine the fabric of the suburb. Lines of idealism make the grid of connecting roads. Lines of utility form the diagonals of the shortest distance from points of energy, the railroad beds and freeways. Lines of romanticism make the winding paths and cul de sacs of the sub-developments, "defensible" dead-ends. The banal image of the forms of the Enlightenment, the rational, of pragmatic and the picturesque are accommodated. The commercial grid holds the field of houses laid out like contour-plowed rows of grain. From an airplane the change from Illinois farm land to the outer suburbs of Chicago is almost imperceptible.

The names of the great suburban sprawls reflect the desire inherent in their form- names like Phoenix or City of Angels. Actually, the formula proposed for the industrial city, UTOPIA + PRAGMATA, works even more smoothly in the postindustrial city.

Ed Soja ${ }^{9}$ proposes that the modern city, in particular Los Angeles, is a conglomeration of heterotopias. A concatenation of "other spaces", illogical, misplaced, at times nonsensical by European standards, addressing both deviance and crisis, form the city. Foucault's categories ${ }^{10}$ respond to the cities discussed here. The pre-Enlightenment city is one of "localization" of internal orders, tight, legible and significant. The industrial city is that of "extension" of the Carte- sian grid and the force of progress. The contemporary city embodies "arrangement" where systems, networks, relations in the post-structuralism sense, produce a software of information and contacts within a web of circuits, saturated with cheap meaning.

The latest NASA fantasy is for a space-station, a city in the sky, safe from motion-sickness, ultimately returning to that sphere that the American city yearns for.

\section{NOTES}

1 This act of ideological conception, - immaculate, cerebral and male - is perceived as synonymous with national generation.

${ }^{2}$ Marx, Karl, "Speech at the Anniversary of The People's Paper", 1856, The Marx-Engels Reader, (New York: Norton,

3 Wharton, Edith, The Age of Innocence, (New York: Random House, 1920) p.64

${ }^{4}$ Sullivan, Louis, The Autobiography of an Idea, 1924 (New York: Dover, 1956) pp. 313-314

s This quote comes from a comment by a Tulane student, Zofia Kondor.

6 Tafuri, Manfredo, "The Disenchanted Mountain: The Skyscraper and the City" in Ciucci, Dal Co, Manieri-Elia, Tafuri, The American City, (Cambridge, MA: MIT, 1973) p.503

7 Perkins, Frances, oral history reminiscences, from Berman, Marshall, All That ls Solid Melts Into Air, (New York: Penguin, 1982), p. 304.

${ }^{8}$ Virilio, Paul, Speed and Politics, (New York: Semiotext[e], 1977) p. 15

${ }^{9}$ Soja, Edward W., Postmodern Geographies: The Reassertion of Space in Critical Social Theory, (London: Verso, 1989)

${ }^{10}$ Foucault, Michel, "Of Other Spaces - the Principles of Heterotopia" Lotus international 48/49 (Milan: Electa, 1985) pp. $8-17$ 